\title{
Correction to: Jejuno-Jejunal Intussusception after Roux-en-Y Gastric Bypass
}

\author{
Brecht Chys ${ }^{1,2} \cdot$ Johan Fierens $^{1} \cdot$ Stefan Sohier ${ }^{1} \cdot$ Ludo Van Krunckelsven $^{1} \cdot$ Lieven Dedrye $^{1}$ \\ Published online: 19 November 2020 \\ (C) Springer Science+Business Media, LLC, part of Springer Nature 2020
}

\section{Correction to: Obesity Surgery \\ https://doi.org/10.1007/s11695-020-04719-6}

In the original article the authors' first and last names were transposed. The original article has been corrected and the names are correct here.

The online version of the original article can be found at https://doi.org/ 10.1007/s1 1695-020-04719-6

\footnotetext{
Brecht Chys

brecht.chys@yperman.net; brechtchys@icloud.com

Johan Fierens

Johan.fierens@yperman.net

Stefan Sohier

Stefan.sohier@yperman.net

Ludo Van Krunckelsven

Ludo.vankrunckelsven@yperman.net

Lieven Dedrye

lieven.dedrye@yperman.net

1 Department of abdominal surgery, Jan Yperman Hospital, Ypres, Belgium

2 Urology, Department of Development and Regeneration, University Hospitals Leuven, Leuven, Belgium
} 